\title{
Adaptation to metal-CONTAMinated solls in POPULATIONS OF THE MOSS, CERATODON PURPUREUS: VEGETATIVE GROWTH AND REPRODUCTIVE EXPRESSION ${ }^{1}$
}

\author{
Erik S. Jules ${ }^{2}$ And A. Jonathan Shaw \\ Department of Biology, University of Michigan, Ann Arbor, Michigan 48109-1048; and \\ Department of Biology, Ithaca College, Ithaca, New York 14850
}

\begin{abstract}
Many observations suggest that morphological evolution occurs slowly in bryophytes, and this has been suggested to reflect low genetic diversity within species. Isozyme studies, however, stand in apparent contrast and have shown that bryophytes can contain high levels of genetic variability within and among populations. In light of this conflict, we tested the potential of the moss, Ceratodon purpureus, to undergo adaptive change (i.e., ecotypic differentiation) in response to soils that have been contaminated with high levels of metals for 90 years by measuring gametophytic growth and reproductive expression under experimental conditions. Variation in protonemal growth in sterile culture indicates that plants from one population growing on contaminated soil near a smelter are significantly more tolerant of zinc, cadmium, and lead than plants from uncontaminated sites. Results from a common garden experiment, in which plants were grown on soil from the smelter site, indicate that plants from near the smelter are significantly more tolerant of contaminated soils than plants from uncontaminated sites for vegetative growth. The same experiment suggests that plants from the smelter site are also more tolerant in terms of gametangial production (although we could not test this statistically). Our results demonstrate that $C$. purpureus has been able to undergo relatively rapid evolution in response to strong selective pressures.
\end{abstract}

Morphological evolution appears to occur slowly in bryophytes. For instance, it has been well documented that geographical disjunctions have resulted in the evolution of distinct yet related species of seed plants, while many bryophytes range broadly across these regions and have seemingly not undergone divergence (Anderson, 1963; Crum, 1972). Furthermore, disjunct populations of bryophytes, often separated by intercontinental distances, can show exceptionally low levels of morphological differentiation (e.g., Schuster, 1972; Shaw, 1993). These and numerous other phytogeographic observations (reviewed in Shaw, 1991) lend strong evidence, albeit inferential, for slow rates of morphological evolution in bryophytes.

Electrophoretic studies indicate that bryophytes contain levels of genetic variability equivalent to those found in seed plants (reviewed in Wyatt, Stoneburner, and Odrzykoski, 1989), and thus a lack of variability is not causing slow rates of morphological differentiation. Interestingly, there is evidence for genetic differentiation among highly disjunct populations that do not appear to differ morphologically (Wyatt, Stoneburner, and Odrzykoski, 1989), and these studies make the lack of morphological differentiation all the more intriguing.

Ecotypic differentiation has been found in only a few species of bryophytes. In these cases, populations found growing on metal-contaminated soils near mine and smelter sites have been found to be significantly more tolerant of metals than populations found on uncontaminated soils (Briggs, 1972; Brown and House, 1978; Shaw, 1988). We studied the potential for a moss, Ceratodon purpureus (Hedw.) Brid., to undergo adaptation to toxic

${ }^{1}$ Manuscript received I February 1993; revision accepted 28 December 1993.

The authors thank Iñigo Granzow, Beverly Rathcke, and Ann Sakai for comments on an earlier draft of the manuscript; and S. C. Beer and Bob Thacker for technical assistance. Support for this research was provided by NSF grant no. BSR-9020126.

${ }^{2}$ Author for correspondence. metals produced by a smelter that has operated for the past 90 years. Our study is unique because no natural deposits of metals were present here before the smelting operation began; the smelter site provides an opportunity to study the rapid evolution of a metal-tolerant ecotype within a known amount of time.

Ceratodon purpureus is a common moss with extremely broad ecological and geographic ranges. The species occurs across North and South America, Europe, northern Asia, Japan, and Hawaii; it is disjunct in Antarctica and the subantarctic Islands (Crum and Anderson, 1981). It occurs on a wide variety of substrates, including moist or dry soil, rock, wood, and sand (Crum, 1973). In temperate North America the species is common along roadsides, both in urban areas and along heavily traveled highways, in fields undergoing secondary succession, in abandoned gravel pits, and on tailings of coal and metal mines in the eastern United States.

The study presented here includes populations of $C$. purpureus from the vicinity of a zinc smelter located in Palmerton, Pennsylvania (Carbon Co.) where current metal concentrations in soils range up to $32,085 \mathrm{ppm}$ zinc, 6,474 ppm lead, and $1,300 \mathrm{ppm}$ cadmium (Nash, 1972; Oyler, 1988). We predicted that $C$. purpureus, a species with such broad ecological tolerances, would be composed of differentially adapted populations, and that the populations from the highly contaminated Palmerton site would be more tolerant of metals than populations from uncontaminated sites. We designed both a sterile agar culture experiment and a common garden experiment to determine the extent to which populations differ in their response to metal-contaminated substrate. Plant performance on agar containing varying concentrations of metals was assessed by measuring the diameter of protonemal growth formed in each dish. Measures of plant performance on soil substrates with varying degrees of metal contamination in the garden experiment were 1) cover area, 2) stem count, and 3) frequency of gametangia. 


\section{MATERIALS AND METHODS}

Garden experiment-Gametophytic samples were collected from four populations of $C$. purpureus. Locality information and plant tissue concentrations are shown in Table 1 (populations 5-8). Plant tissue samples from each population were analyzed for metal content in the Plant Nutrition Laboratory, Department of Pomology, Cornell University (see Shaw, Beer, and Lutz, 1989 for details). Plant tissue concentrations were used because some populations (e.g., Roof) did not have sufficient substrate for analysis. Nonetheless, tissue concentrations should reflect the amount of metals in underlying substrates and are sufficient for making comparisons among populations (Shacklette, 1965). The "Smelter" population (pop. 8) was collected on Blue Mountain, directly downwind from a zinc smelter (consequently, Blue Mountain has the highest level of metal contamination in the Palmerton area; $\mathbf{J}$. Oyler, Horsehead Resource Development Corporation, personal communication). Soil from near the Smelter population was collected for experimental use.

Plant samples were cleaned of substrate material, dried, and ground in a blender. This method allows subsequent protonemal growth to begin from a random selection of gametophyte fragments, and furthermore reduces carryover effects. Ground plant material $(0.1 \mathrm{~g})$ from each population was evenly spread over each of four replicates of three soil types (treatments) in $1^{\prime \prime} \times 1^{\prime \prime}$ pots. Treatments included 1) a "control" of sterilized Turface (crushed clay), 2) "contaminated" soil from Palmerton, Pennsylvania (sterilized and sifted), and 3) a "mixture" of one volumetric part control to one part contaminated soil. Unlike the agar experiment (to be described below), this study did not test for tolerance of specific metals, but rather attempted to reproduce field conditions. The contaminated treatment included concentrations of metals equivalent to those found in the soil on which the Smelter population originated (Table 1). Populations, treatments, and replicates were completely randomized within a common $1^{\prime} \times 2^{\prime}$ greenhouse tray. The experiment was maintained in a growth chamber with a temperature of $27 \pm$ $3 \mathrm{C}$ and a photoperiod of $13 \mathrm{hr}$.

After 3 mo of growth, each pot was examined under a stereomicroscope. Population, treatment, and replicate information were unknown until after measurements were obtained for each pot. A cover area index, including both cover area of protonema and stem material, was estimated on a scale of 0-10 $(0=$ no growth, $10=$ area in pot completely covered). The total number of stems was also counted in each pot. After 5 mo of growth, 15 randomly selected stems from each pot were scored for the presence or absence of gametangia (archegonia or antheridia) under a stereomicroscope. Overall sex expression was estimated for each pot by calculating the total number of gametangia (archegonia or antheridia)/ 15 .

Differences in metal tolerance among populations were determined by comparing responses of cover area index, stem count, and sex expression over the three treatments. Significant population $\times$ treatment interactions, analyzed using an analysis of variance, indicate differential responses to the treatments among populations, and provide evidence of potential differences in tolerance. Population main effects in the ANOVA indicate variation in gener-
TABLE 1. Locality information and metal concentrations (ppm) in plants from populations of Ceratodon purpureus used in experimental studies on agar (pops. 1-4) and soil substrates (pops. 5-8). "-" means values were below detection limits.

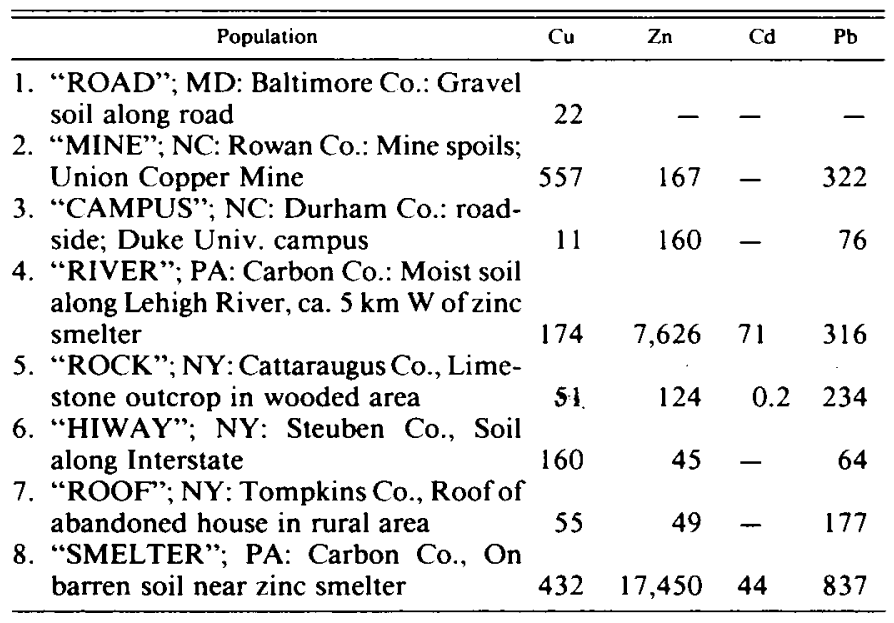

alized growth rate, not metal tolerance, across experimental treatments. All tests in the garden experiment were performed using SYSTAT (Wilkinson, 1990).

Agar experiment-Collections were made of gametophytic material from four other populations of $C$. purpureus. Locality information and plant tissue concentrations of copper, zinc, cadmium, and lead are shown in Table 1 (populations 1-4). The "River" population (pop. 4) from the Palmerton area was found along the Lehigh River, approximately $5 \mathrm{~km}$ downstream from the smelter and the Smelter population.

One leaf or leaf fragment of 15 gametophytes from the four populations was surface sterilized by a 1-2-sec wash in $50 \%$ bleach, then $3-5 \mathrm{sec}$ in $30 \% \mathrm{ETOH}$ with one to two drops of Tween 80 , and finally a sterile water rinse. Each leaf was transferred to a petri dish containing a modified Hoagland's nutrient medium solidified with $1.2 \%$ agar (see Shaw, Beer, and Lutz, 1989).

The plants were allowed to grow in sealed petri dishes for 2 mo under uniform conditions in order to eliminate possible carry-over of environmental effects. After this period, protonema had formed a circular mat and some individuals had also formed stems. Although bacterial and/or fungal contamination of cultures initiated from field-collected gametophytes is extremely difficult to eliminate, at least two individuals from each population appeared to be free of contamination. Thus, two representatives per population were chosen for the metal-tolerance experiments.

A uniform portion ( $1 \mathrm{~mm}$ diameter) of protonema from each individual was transferred to the center of new petri dishes containing the following media: a control (modified Hoagland's medium - see above), and the control supplemented with one of the following: 2,4 , or $6 \mathrm{ppm} \mathrm{Cu}$ (as $\mathrm{CuSO}_{4}$ ); 40,60, or $80 \mathrm{ppm} \mathrm{Zn}\left(\right.$ as $\mathrm{ZnCl}_{2}$ ); 150, 200, or $250 \mathrm{ppm} \mathrm{Pb}\left(\right.$ as $\left.\mathrm{PbNO}_{3}\right) ; 0.05,0.10$, or $0.25 \mathrm{ppm} \mathrm{Cd}$ (as $\mathrm{CdCl}_{2}$ ). Based on preliminary studies, metal concentrations were selected to span a range from low toxicity to concentrations known to inhibit growth. Similar methods have been used in several other studies (Shaw, 1988; 

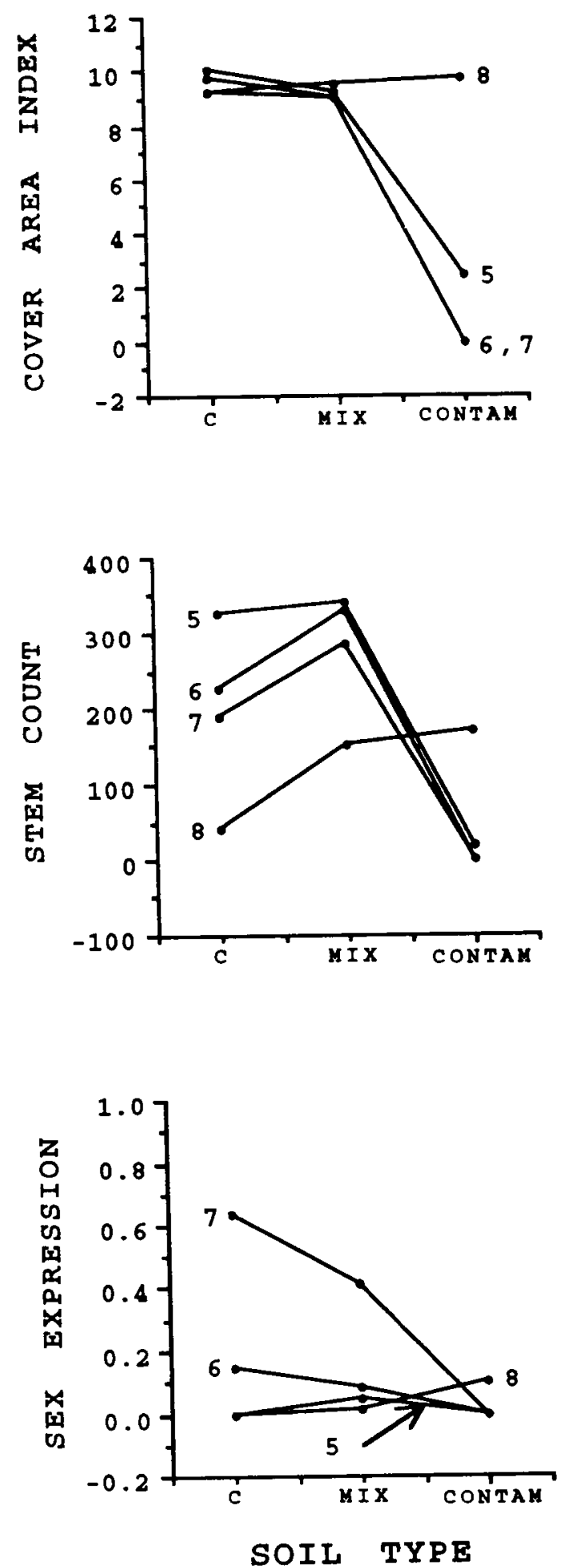

Fig. 1. Mean cover area index, stem count, and sex expression (total gametangia/total stems) in four populations of $C$. purpureus grown on three treatments (soil-types). Populations 5-7 originated on uncontaminated soils, and population 8 originated on metal-contaminated soil. See Table 1 for additional population data.

Shaw and Albright, 1990). Each individual was grown on three replicate petri dishes of each treatment. The individuals and treatments were completely randomized within three replicate blocks, and the experiment therefore
TABLE 2. Analysis of variance of cover area index for four populations of C. purpureus grown on control, mixture, and contaminated soil.

\begin{tabular}{lrrrr}
\hline \multicolumn{1}{c}{ Source } & df & MS & \multicolumn{1}{c}{$F$} & \multicolumn{1}{c}{$\boldsymbol{P}$} \\
\hline Pop. & 3 & 29.7 & 33.7 & $<0.0001$ \\
Treat. & 2 & 213.1 & 241.6 & $<0.0001$ \\
Pop. $\times$ treat. & 6 & 28.1 & 31.8 & $<0.0001$ \\
Error & 36 & 0.88 & & \\
\hline
\end{tabular}

consisted of: four populations $\times$ two individuals per population $\times 13$ treatments $\times$ three clonal replicates, giving a total of 312 petri dishes.

Plants were grown on growth racks with a 16-hr photoperiod with the temperature outside the dishes maintained at $23 \pm 3 \mathrm{C}$. After $1 \mathrm{wk}$ the diameter of the protonemal mat in each dish was measured, and measurements were repeated at weekly intervals for $4 \mathrm{wk}$ thereafter to estimate protonemal growth rates for each individual.

Variation in tolerance among populations was assessed by analyzing the data in two ways. First, tolerance among populations was analyzed by comparing responses to the three concentrations of each metal. Significance of the population $\times$ treatment interaction term was analyzed using an analysis of variance. Tolerance was also estimated from growth rates on control medium and on the highest levels of each metal treatment. Using a repeated measures analysis of variance, growth rates were compared by estimating the population protonemal diameter $x$ wk of measurement interaction term. We used the Wilks' Lambda statistic from this analysis to determine significance. In both tests described above, significance of population differences were tested against the individuals within population interaction term. All tests in the agar experiment were performed using SAS (SAS Institute, Inc., 1982).

\section{RESULTS}

Garden experiment - There were no significant differences in cover area index among populations grown on both the control and mixture soils (Fig. 1). Plants from two populations collected from uncontaminated soils (Roof and Hiway) had no growth on the contaminated treatment, and a third population (Rock) was severely reduced on the contaminated treatment. The cover area index for the Smelter population, however, was higher on the contaminated soil than on control or mixture, although this difference was not statistically significant. On contaminated soil the Smelter plants grew significantly more cover area than the only other living population $(t$ $=4.95, \mathrm{df}=3.2, P=0.014)$. An analysis of variance

TABLE 3. Analysis of variance of stem count for four populations of C. purpureus grown on control, mixture, and contaminated soils.

\begin{tabular}{lrrrr}
\hline \multicolumn{1}{c}{ Source } & df & \multicolumn{1}{c}{ MS } & \multicolumn{1}{c}{$F$} & $P$ \\
\hline Pop. & 3 & $24,102.0$ & 14.6 & $<0.0001$ \\
Treat. & 2 & $217,310.0$ & 131.6 & $<0.0001$ \\
Pop. $\times$ treat. & 6 & $44,078.0$ & 26.7 & $<0.0001$ \\
Error & 36 & $1,650.0$ & & \\
\hline
\end{tabular}



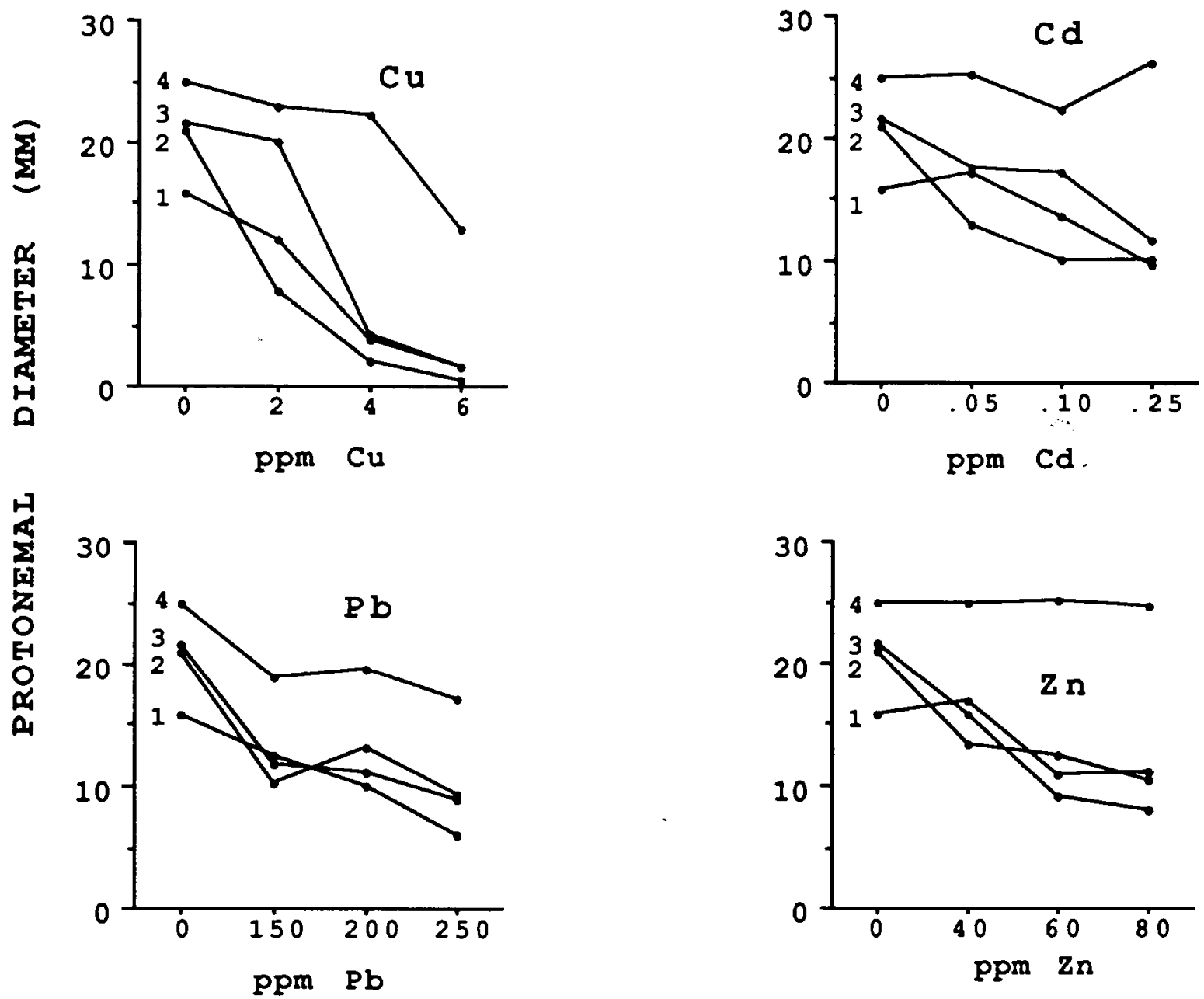

\section{TREATMENT}

Fig. 2. Mean diameter of the protonemal mat in four populations of $C$. purpureus grown on three concentrations each of $\mathrm{Cu}, \mathrm{Zn}, \mathrm{Cd}$, and $\mathrm{Pb}$ for 5 wk. Populations 1-3 originated on uncontaminated soils, and population 4 originated on metal-contaminated soil. See Table 1 for additional population data.

demonstrates that the population $\times$ treatment interaction is significant for the cover area index (Table 2).

Smelter plants produced significantly more stems on contaminated soils than on control soil (Fig. $1 ; t=10.79$, $\mathrm{df}=4, P<0.001$ ), and they grew significantly more stems on contaminated soil than even the most vigorous of the other three populations $(t=7.92, \mathrm{df}=5.3, P<0.001)$. All other populations were severely reduced on the contaminated treatment. An analysis of variance demonstrates that the population $\times$ treatment interaction was significant for stem count (Table 3). Interestingly, Smelter plants produced significantly fewer stems than even the least vigorous of the other three populations on the control soil $(t=2.81, \mathrm{df}=5.2, P=0.036)$.

Plants from the Smelter population did not produce gametangia on the control soil (Fig. 1). However, the proportion of stems of Smelter plants exhibiting sex expression was 0.017 on the mixture treatment and 0.1 on the contaminated treatment. In contrast, sex expression in the other three populations was reduced on the mixture treatment, and no gametangia were produced by these populations on the contaminated treatment. Although there was insufficient data to perform an analysis of variance, the trends are strongly suggestive of differential responses of populations in terms of reproductive behavior.

Agar experiment-Population responses to the three concentrations of each metal, measured as the mean diameter of the protonemal mat at week five, are shown in Fig. 2. Plants from the River population were less inhibited by all four metals than plants from the other populations. Growth of River plants was not inhibited even at the highest concentrations of zinc and cadmium, whereas growth of plants from the other populations was severely reduced by these same levels of metals. At $4 \mathrm{ppm}$ copper, plants other than those from the River population showed approximately $50 \%$ inhibition, and grew very little on $6 \mathrm{ppm}$ copper. River plants were unaffected by 4 ppm copper, but on $6 \mathrm{ppm} \mathrm{Cu}$ their growth was inhibited by almost $50 \%$.

Significance of differences among populations in response to the three concentrations of each metal was tested 
TABLE 4. Summary of the population $x$ treatment interactions (ANOVA) for protonemal diameter in plants from four populations of C. purpureus grown on agar with three concentrations each of copper, zinc, cadmium, and lead. "ns" indicates no significant difference.

\begin{tabular}{lllll}
\hline \hline \multicolumn{1}{c}{ Metal } & df & MS & $F$ & \multicolumn{1}{c}{$P$} \\
\hline Copper & 7 & 90.6 & 1.25 & ns \\
Zinc & 7 & 59.9 & 3.11 & 0.0354 \\
Cadmium & 7 & 46.9 & 2.27 & ns \\
Lead & 7 & 17.4 & 0.61 & ns \\
\hline
\end{tabular}

by the population $\times$ treatment (metal concentration) interactions (Table 4$)$. The interaction was significant only for zinc $(P<0.04)$. Differences were attributable to the high tolerance exhibited by the River plants (see Fig. 4). Although the River population did not have a significantly greater tolerance to cadmium at week five, it was significant for weeks 1 and 4 (statistics not shown). The greater protonemal growth of River plants on zinc is clearly evident from Fig. 2, which also shows that River plants tended to be more tolerant of cadmium, lead, and copper.

Differences in tolerance among populations were also evident when rates of protonemal growth over the 5-wk period were compared (Figs. 3,4). On the control medium, all four populations grew at approximately the same rate. However, on all of the media enriched with metals, the River plants grew faster than the other three populations. A repeated measures ANOVA for growth rates (Table 5) showed that populations differed significantly in growth rate on media enriched with zinc $(P=0.0141)$, cadmium $(P=0.012)$, and lead $(P=0.0199)$, although not on control or copper-enriched media. Significant differences were clearly due to the relatively high growth of River plants on metal-enriched media.

\section{DISCUSSION}

Preliminary evidence suggested that populations of $C$. purpureus originating on moderately metal-contaminated soils do not evolve metal-tolerant ecotypes (Shaw, Jules, and Beer, 1991), but we reasoned that ecotypic differentiation might occur on more highly metal-contaminated soils where selection is more intense (Lefébvre and Vernet, 1990). Therefore, the study here includes populations found on the highly metal-contaminated soils of Palmerton, Pennsylvania. The two populations we studied from the Palmerton area represent a metal-tolerant ecotype, and C. purpureus thus clearly contains genetic variability for tolerance of metals. High levels of metal-tolerance in the River plants were evidenced in significantly lower growth inhibition in relation to increasing amounts of zinc, and in higher protonemal growth rates on media supplemented with zinc, cadmium, and lead. Plants from the Smelter population had relatively higher tolerance to metals for cover area, stem production, and gametangial formation. The high levels of tolerance in Palmerton plants are almost certainly a response to natural selection caused by smelter emissions, although evidence of a causative role for selection is indirect.

The evolution of metal-tolerant ecotypes in flowering plants has been thoroughly reviewed (Antonovics, Brad-

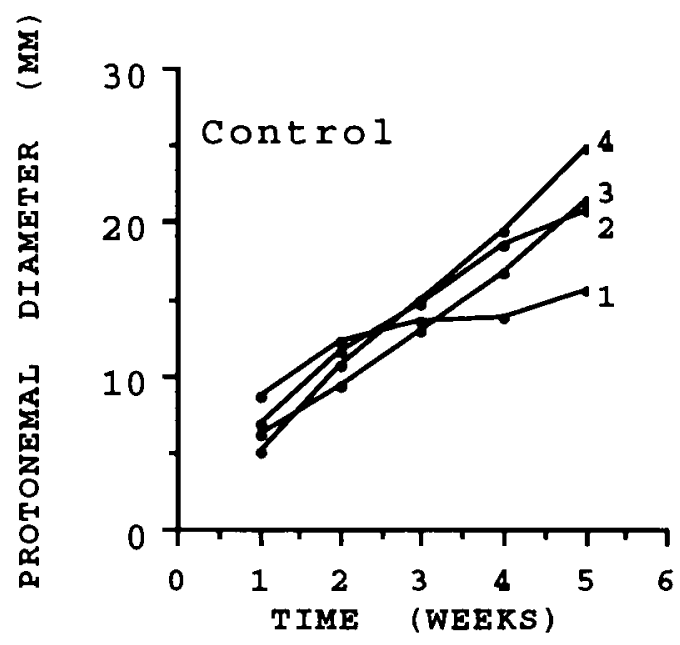

Fig. 3. Protonemal growth curves for four populations of C. purpureus grown on control medium. Populations $1-3$ originated on uncontaminated soils, and population 4 originated on metal-contaminated soil. See Table 1 for additional population data.

shaw, and Turner, 1971; Baker, 1987; Shaw, 1990a). Localized selection pressures can cause the rapid evolution of tolerance within well-defined geographic areas. Lefébvre (unpublished data, cited in Lefébvre and Vernet, 1990) cleared a meadow plot $2 \mathrm{~m}^{2}$ and $30 \mathrm{~cm}$ deep of all vegetation, and then applied $1 \mathrm{~kg} / \mathrm{m}^{2} \mathrm{ZnSO}_{4} \cdot 7 \mathrm{H}_{2} \mathrm{O}$. After $3 \mathrm{yr}$, a population of Agrostis capillaris Sibth. had colonized the area, and this population had a mean tolerance index for zinc twice that of the surrounding population. Wu and Bradshaw (1972) demonstrated a positive correlation between mean copper tolerance in populations of Agrostis stolonifera L., and the length of time in which plants were contaminated with copper from a metal refinery. The disappearance of the least tolerant plants occurred within $14 \mathrm{yr}$, and a shift in the mean tolerance level of populations was found in populations only $4 \mathrm{yr}$ of age.

In contrast to angiosperms, metal-tolerant ecotypes have been demonstrated in only two liverworts, Marchantia polymorpha L. (Briggs, 1972) and Solenostoma crenulata (Sm.) Mitt. (Brown and House, 1978), and one moss, Funaria hygrometrica Hedw. (Shaw, 1988). Funaria hygrometrica forms copper-tolerant ecotypes, although tolerance to other metals (e.g., zinc and cadmium) appears to be due mostly to cross-tolerance and generally vigorous growth (Shaw, 1990b). This differs from the highly metalspecific response in flowering plants. Shaw and Albright (1990) found a lack of ecotypic differentiation among populations of the moss, Bryum argenteum $\mathrm{Hedw}$., found growing on soils with varying degrees of metal concentrations. Similarly, Longton (1981) found that populations of $B$. argenteum from several different geographic regions, for example, Hawaii and Antarctica, did not differ in their response to temperature. Potentially, bryophytes may differ from angiosperms in that they employ higher levels of phenotypic plasticity, rather than small-scale genetic responses, to adapt to heterogeneous environments. The evidence available at present, though, is much too limiting to make strong conclusions.

The Palmerton area provides a unique opportunity to 

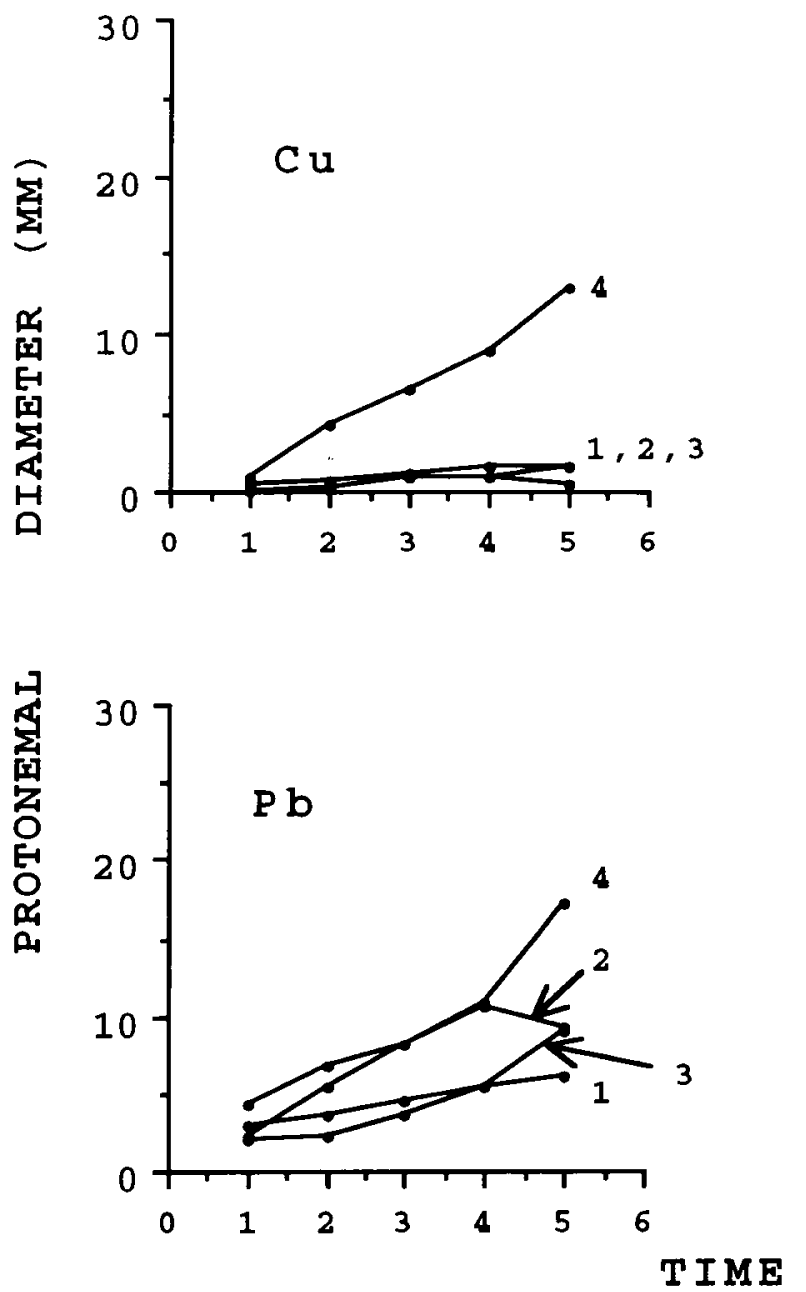
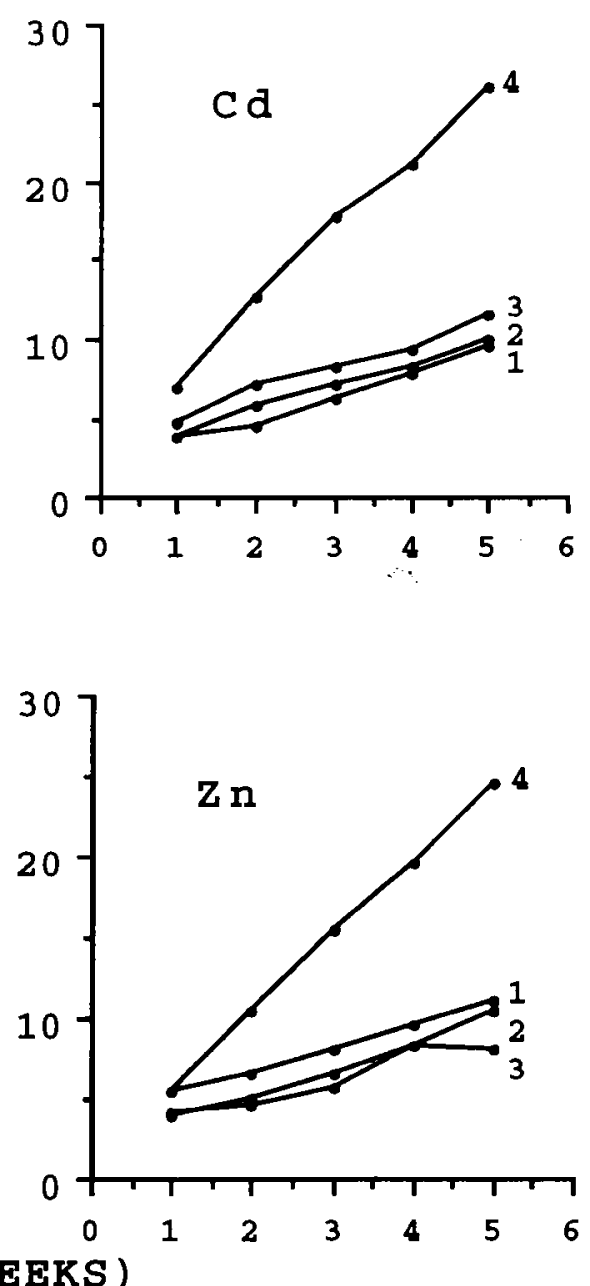

Fig. 4. Protonemal growth curves for four populations of $C$. purpureus grown on medium enriched with either $\mathrm{Cu}(6 \mathrm{ppm}), \mathrm{Zn}(80 \mathrm{ppm})$, $\mathrm{Cd}$ $(0.25 \mathrm{ppm})$, or $\mathrm{Pb}(250 \mathrm{ppm})$. Populations 1-3 originated on uncontaminated soils, and population 4 originated on metal-contaminated soil. See Table 1 for additional population data.

estimate the time in which ecotypic differentiation may occur. The first of two zinc smelters in Palmerton began operation in 1898, the second in 1912 (Buchauer, 1973). Unlike the sites used in many previous studies, no natural deposits of metals existed in the Palmerton area prior to the initiation of smelting. Therefore, the approximate date of contamination is known for the Palmerton area, and we can conclude that the tolerant populations must have evolved within a 90 -yr period.

The evolutionary events that followed contamination by smelting operations could have involved several possibilities, or a combination of these. Ceratodon purpureus may not have grown in the area before contamination. In this case, destruction of the original forest community would have provided a suitable, disturbed habitat for $C$. purpureus. Due to metal emissions from the smelter, only tolerant individuals colonizing the area would have survived. Alternatively, $C$. purpureus could have been native in the area prior to operation of the zinc smelter. The original population may have contained metal-tolerant plants at a low frequency, as reported in several higher plants (Macnair, 1987). Progressive elimination of nontolerant individuals would then shift the population mean toward increased tolerance, as in the case described by Wu and Bradshaw (1972). Although these two alternatives cannot be distinguished by our data, the evolutionary consequences could be quite different. In the first case, the Palmerton populations of $C$. purpureus would have been founded by one or a few individuals, implying a severe population bottleneck. The second possibility, in contrast, would involve a progressive reduction in population variability, with no bottleneck per se.

TABLE 5. Summary of population $\times$ time (wk of measurement) from repeated measures analyses of variance for protonemal diameter in plants from four populations of $C$. purpureus grown for $5 \mathrm{wk}$ on control medium, and on the control supplemented with copper $(6$ ppm), zinc (80 ppm), cadmium $(0.25 \mathrm{ppm})$, or lead (250 ppm). "ns" indicates no significant difference.

\begin{tabular}{llcll}
\hline \hline Treatment & df & MS & $F$ & \multicolumn{1}{c}{$P$} \\
\hline Control & 12 & 29.9 & 1.68 & ns \\
Copper & 12 & 26.4 & 1.31 & ns \\
Zinc & 12 & 44.8 & 5.53 & 0.0001 \\
Cadmium & 12 & 38.5 & 3.45 & 0.0012 \\
Lead & 12 & 24.7 & 3.29 & 0.0020 \\
\hline
\end{tabular}


Our garden experiment results also give some indication that there might be a biological cost associated with metaltolerance in C. purpureus. Smelter plants produced fewer stems and fewer gametangia on the control treatment than on the contaminated treatment. Although this result may in fact be due to other differences between the control soil and the Palmerton soil (e.g., nutrient content), our evidence is suggestive of a cost. Similarly, Shaw (1990b) demonstrated that metal-tolerant $F$. hygrometrica individuals form stems more slowly on normal (uncontaminated) treatments than nontolerant individuals. Metaltolerant angiosperms also incur a cost; plants tolerant of metals are found to be competitively inferior on uncontaminated soils and thus occur in low frequencies in the absence of metal contamination (Bradshaw, 1976).

Although the evolution of tolerant ecotypes in bryophytes has been previously demonstrated, the work reported here is the first to place bryophyte evolution within a known time scale. Two populations of $C$. purpureus have evolved tolerance to metals within $90 \mathrm{yr}$, apparently in response to strong selective pressures exerted by metal emissions from a local smelter. Our work augments evidence for genetic variability produced by electrophoretic studies (Wyatt, Stoneburner, and Odrzykoski, 1989) and other studies of metal tolerance in bryophytes (Briggs, 1972; Brown and House, 1978; Shaw, 1988). These studies stand in noticeable contrast to earlier assumptions, based on morphological observations, that genetic variation within bryophyte species is low and that population differentiation is rare. We believe that one of the most intriguing unanswered questions in the evolutionary biology of these organisms is what factors constrain morphological evolution in spite of a plentiful amount of genetic variability within species.

\section{LITERATURE CITED}

ANDERSON, L. E. 1963. Modern species concepts: mosses. Bryologist 66: 107-119.

Antonovics, J., A. D. Bradshaw, and R. G. Turner. 1971. Heavy metal tolerance in plants. Advances in Ecological Research 7: 1-85.

BAKER, A. D. 1987. Metal tolerance. New Phytologist 106: 93-111.

Bradshaw, A. D. 1976. Pollution and evolution. In T. A. Mansfield [ed.], Effects of air pollutants on plants, 135-159. Cambridge University Press, Cambridge.

BRIGoS, D. A. 1972. Population differentiation in Marchantia polymorpha L. in various lead pollution levels. Nature 238: 166-167.

Brown, D. H., AND K. L. House. 1978. Evidence of a copper tolerant ecotype of the hepatic Solenostomum crenulatum. Annals of Botany 42: 1383-1392.

BUCHAUER, M. J. 1973. Contamination of soil and vegetation near a zinc smelter by zinc, cadmium, copper, and lead. Environmental Science and Technology 2: 131-135.
Crum, H. A. 1972. The geographic origins of the mosses of North America's eastern deciduous forest. Journal of the Hattori Botanical Laboratory 35: 269-298.

- 1973. Mosses of the Great Lakes Forest. Contributions to the University of Michigan Herbarium 10: 1-404.

- AND L. E. ANDERSON. 1981. Mosses of eastern North America. Columbia University Press, New York, NY.

LefÉBVRE, C., AND P. VERNET. 1990. Microevolutionary processes on contaminated deposits. In A. J. Shaw [ed.], Heavy-metal tolerance in plants: evolutionary aspects, 285-300. CRC Press, Boca Raton, FL.

LONGTON, R. E. 1981. Inter-population variation in morphology and physiology in the cosmopolitan moss Bryum argenteum Hedw. Journal of Bryology 11: 501-520.

MACNAIR, M. R. 1987. Heavy metal tolerance in plants: a model evolutionary system. Trends in Ecology and Evolution 2: 354-359.

NASH, E. 1972. Effects of effluents from a zinc smelter on mosses. Ph.D. dissertation, Rutgers University. New Brunswick, NJ.

OYLER, J. A. 1988. Reclamation of a site near a smelter using sludge/ fly ash amendments: herbaceous species. Presented at Surface Mine Reclamation Conference, Pittsburgh, PA.

SAS INSTITUTE, INC. 1982. SAS users guide: statistics. SAS Institute, Inc., Cary, NC.

SCHUSTER, R. M. 1972. Evolving taxonomic concepts in the Hepaticae, with special reference to circum-Pacific taxa. Journal of the Hattori Botanical Laboratory 35: 169-201.

Shacklette, H. T. 1965. Element content of bryophytes. U.S. Geological Survey Bulletin 1198d: 1-18.

SHAw, A. J. 1988. Genetic variation for tolerance to copper and zinc within and among populations of the moss, Funaria hygrometrica Hedw. New Phytologist 109: 211-222.

- [ED.]. 1990a. Heavy metal tolerance in plants: evolutionary aspects. CRC Press, Boca Raton, FL.

- 1990b. Metal tolerances and cotolerances in the moss, Funaria hygrometrica Hedw. Canadian Journal of Botany 68: 2275-2282. . 1991. Ecological genetics, evolutionary constraints, and the systematics of bryophytes. Advances in Bryology 4: 29-74.

. 1993. Morphological uniformity among widely disjunct populations of the rare "copper moss," Scopelophila cataractae (Pottiaceae). Systematic Botany 18: 525-537.

- AND D. L. Albright. 1990. Potential for the evolution of heavy metal tolerance in Bryum argenteum, a moss. II. Generalized tolerances among diverse populations. Bryologist 93: 187-192.

- , S. Beer, and J. Lutz. 1989. Potential for the evolution of heavy metal tolerance in Bryum argenteum, a moss. I. Genetic variation within and among urban populations. Bryologist 92: 7380.

- E. S. JuLES, AND S. C. BEER. 1991. Effects of metals on growth, morphology, and reproduction of Ceratodon purpureus. Bryologist 94: 270-277.

WILKINSON, L. 1990. SYSTAT: the system for statistics. SYSTAT, Inc., Evanston, IL.

Wu, L., AND A. D. Bradshaw. 1972. Aerial pollution and the rapid evolution of copper tolerance. Nature 238: 167-169.

Wyatt, R., A. Stoneburner, ANd I. J. Odrzykoski. 1989. Bryophyte isozymes: systematic and evolutionary implications. In D. E. Soltis and P. S. Soltis [eds.], Isozymes in plant biology, 221-240. Dioscorides, Portland, OR. 